\title{
Detection of Precancerous Cells and Incidence of Human Papillomavirus among Women of Reproductive Age Attending Selected Hospitals in Katsina
}

\author{
Abdulkadir B ${ }^{1}$, Hayatudeen M. $\mathrm{R}^{{ }^{*}}$, Munir R. $\mathrm{G}^{1}$, Aminu $\mathrm{M}^{2}$, Shuaibu $\mathrm{M}^{3}$, Abdulkarim $\mathrm{B}^{4}$, Oyero, S. $\mathrm{K}^{5}$ \\ ${ }^{1}$ Department of Microbiology, Faculty of Science, Umar Musa Yar'adua University, Katsina \\ ${ }^{2}$ Department of Microbiology, Faculty of Science, Ahmadu Bello University Zaria, Nigeria \\ ${ }^{3}$ Department of Histopathology, Federal Medical Center Katsina, Katsina Sate, Nigeria \\ ${ }^{4}$ Department of Biology, Faculty of Science, Umaru Musa Yar adua University, Katsina \\ ${ }^{5}$ Department of Histopathology, Jos University Teaching Hospital, Jos Plateau State, Nigeria
}

\begin{abstract}
DOI: $10.36348 /$ sipm.2021.v06i01.008
| Received: 25.04.2019 | Accepted: 04.05.2019 | Published: 23.01.2021
\end{abstract}

*Corresponding author: Hayatudeen M. R

\section{Abstract}

Infection with oncogenic or high risk human papillomavirus (hrHPV) types significantly triggers the development of cervical cancer. Cervical cancer is the most common female cancer in northern Nigeria, yet the pattern of infection with human papillomavirus, the principal aetiologic agent is unknown; besides, prevalence data that governs research and policy is often inadequate or nonexistent. This study aims to detect precancerous cells and elucidate the incidence of HPV in cervical cancer among women attending selected hospitals in Katsina State. This was a preliminary study conducted in two hospitals in order to establish base-line data on the incidence and risk factors for the infection in Katsina State, Nigeria. The employed study design was Hospital based and cross sectional, involving the use of structured questionnaires to obtain socio-demographic and clinical data. Sixty (60) randomly selected women aged 18 years and above were recruited from gynaecology clinics in General Hospital, Katsina and Turai Umar Yar'adua Maternal and Children Hospital (TUYMCH). Relevant sexual and socio-demographic information were obtained from each subject using a questionnaire. Sixty (60) cervical scraping samples were screened for both HPV and squamous intraepithelial llesion (SIL) using enzyme linked immunosorbent assay and conventional Papsmear, respectively. Data is presented in tables, and analyzed using the Graphpad Prism statistical software, version 69, at 0.05 level of significance and $95 \%$ confidence interval. The incidence rate of HPV infection obtained from ELISA test was 35\% [(21/60)] and also $33.2 \%$ [(20/60)] with abnormal cytology results. Risk factors of the infection include low literacy levela; living in rural settlements; low parity; early menarche ( $<15$ years of age); early onset of first sexual intercourse ( $\leq 16$ years of age) and multiple sexual partners with $48 \%$. There was however, no statistically significant association between oral contraceptive usage and acquisition of the infections. The findings from this study have shown that there is a high possibility of detecting the DNA of hrHPV in women that are infected with HPV and those that have cervical dysplasia, which points out the possibility of these women developing cervical cancer. Further studies should be done using molecular screening techniques such as the linear Array, HPV Genotyping, and molecular characterization of HPV.

Keywords: Human Papillomavirus; incidence; prevalence; DNA.

Copyright (C) 2021 The Author(s): This is an open-access article distributed under the terms of the Creative Commons Attribution 4.0 International License (CC BY-NC 4.0) which permits unrestricted use, distribution, and reproduction in any medium for non-commercial use provided the original author and source are credited.

\section{INTRODUCTION}

Human papillomavirus (HPV) infection is a prominent concern in both research and medical fields. It is the most common sexually transmitted infection affecting sexually active women at some point in their lives [1, 2]. Although HPV has been associated with many diseases, it's association with cervical cancer has particular significance being the principal cancer in most development countries [1].

The prevalence of cervical infection with HPV in women varies greatly in the African continent where some of the highest rates are found. Population based HPV prevalence survey shows a wide range variation in the HPV prevalence of HPV infection among sexually active women aged 15-65 years, ranging from $20 \%$ in 
Abdulkadir B et al; Saudi J Pathol Microbiol, Jan, 2021; 6(1): 40-45

Hanoi [3], 14.8\% in Bagota, Columbia [4] to $26.3 \%$ in Ibadan, Nigeria [5] and 66.1\% in Burkina faso [6]. In northern Nigeria cervical cancer have a relatively high prevalence [7]. However the prevalence and risk factors for acquisition of HPV infection have not been documented.

The objective of this study was to detect pre cancerous cells and determine the incidence of Human Papilloma virus in cervical cancer among women of reproductive age attending gynaecology clinics Katsina, Northern Nigeria.

\section{MATERIALS AND METHODS Study Area}

The study was carried out among women of reproductive age attending some selected hospitals in Katsina Local Government Area, which is a Local Government in the Katsina Central Senatorial Zone. The zone also contains the following Local Government Areas, in addition to Katsina: Batagarawa, Rimi, Jibiya, Charanchi, Batsari, Kaita and Kurfi.

The sampled hospitals the study was based in were: General Hospital, Katsina and Turai Umaru Yar'adua Children and Maternity Hospital, Katsina. Predominantly, people populating the area are HausaFulani and Muslims, although other tribes/religions may be found in the minority. Katsina shares borders with Batagarawa, Batsari, Jibiya, Kaita and Mani Local Governments. It has a population of 429,400 , as an approximate value, as of 2016 [8].

\section{Study Design}

A perspective cross sectional study was carried out on women of reproductive age who present for HPV screening in the study area with a view to ascertaining both their HPV status and the elucidation of certain risk factors associated with the ailment via the administration of a questionnaire.

\section{Sample Size Determination}

The sample of 60 women aged 18 years and above among patients attending gynaecology clinics at General Hospital Katsina (GHK) and Turai umar musa yar'adua maternal and children hospital (TUYMCH) size was determined using the equation described by Sar Mukaddam and Garad [9].

\section{Inclusion Criteria}

This study included women of reproductive age, from age 18 onwards. Women who gave their consent alone were included in the research.

\section{Exclusion Criteria}

Women under 15 and non-childbearing were excluded from the study. Excluded also were women who refused consent, pregnant women, posts hysterectomy, post-cervical conisation, physically or mentally challenged women and women bleeding per vaginum were excluded [5].

\section{Ethical Clearance and Consent}

Ethical approval for the study was obtained

from Ministry of Health, Katsina State, (MOH/ADM/SUB/1152/1/212), before the commencement of the study. Furthermore, each client were given a consent form to know the research purpose and what samples to give, and samples were collected only from consenting patients.

\section{Sample Collection and processing}

A total of 60 blood samples were aseptically collected using syringes from the respondents with the assistance of professional health workers. The whole blood was allowed to clot for at least 30mins and then centrifuged at $1000 \mathrm{rmp}$ for $10 \mathrm{mins}$. The serum was carefully removed with a transfer pipette and transferred aseptically into a sterile labeled serum storage screw capped container. It was then stored in a freezer for further analysis at a temperature of -4 degrees Celsius.

The samples were then transported in an ice packed to the Biotechnology and Research Center, Ahmadu Bello University Zaria (ABU). A Pap smear was performed by opening the vaginal canal with a speculum. Subsequently, cells at the outer opening of the cervix were collected at the transformation zone (where the outer squamous cervical cells meet the inner glandular endocervical cells). The sample were fixed with $95 \%$ alcohol on a glass slide. Finally, the collected cells were examined under a microscope to observe abnormalities in the cells.

\section{Data and Result Presentation}

The data collected from the structured questionnaire and laboratory analysis was presented using descriptive statistics, and analysed using the statistical tool: Graph Pad Prism Statistical Software (GPPSS) version 69. The results were presented in both tables and charts. Chi-square test and Odds ratio were used at 0.05 significance level and at 95\%confidence intervals to test for statistical association between HPV positivity and the risk factors for HPV infection.

\section{RESULTS}

Analysis of ELISA result showed that $35 \%$ $(21 / 60)$ of the women were positive for HPV antigen, while 65\%(39/60) were negative. Age ranges from 21$30(20 \%)$ have high incidence followed by 31-40 $(8.3 \%)$, then $41-59(5 \%)$ and a low incidence is observed within 10-20 (1.6\%). The total of 60 women screened for cervical cancer $40(66.7 \%)$ had normal cytole, while $20(33.2 \%)$ had some form of abnormal cytology result, with ASC-US having highest percentage (13.3\%). The results obtained from papsmear shows that there is significant difference between women with positive papsmear and those with negative result. 
Abdulkadir B et al; Saudi J Pathol Microbiol, Jan, 2021; 6(1): 40-45

Table-1: Age of respondents, Their Number and Incidence of HPV

\begin{tabular}{llll}
\hline Age ranges & No. of women & Positive (\%) & Negative (\%) \\
\hline $10-20$ & 6 & $1(1.6 \%)$ & $4(6.6 \%)$ \\
$21-30$ & 32 & $12(20 \%)$ & $20(33.3 \%)$ \\
$31-40$ & 18 & $5(8.8 \%)$ & $13(21.6 \%)$ \\
$41-50$ & 4 & $3(5 \%)$ & $2(3.3 \%)$ \\
Total & $\mathbf{6 0}$ & $\mathbf{2 1}(\mathbf{3 5 \%})$ & $\mathbf{3 9}(\mathbf{6 5 \%})$ \\
\hline \multicolumn{4}{r}{$\mathrm{P}=<0.05, \mathrm{df}=3$, mean $=3.77$}
\end{tabular}

Table-2: Cytology result of respondents and frequency

\begin{tabular}{ll}
\hline Cytological classes & Frequency \\
\hline Abnormal & $20(33.2 \%)$ \\
ASC-US & $8(13.3 \%)$ \\
LSIL & $6(10 \%)$ \\
HSIL & $2(3.3 \%)$ \\
SCC & $4(6.6 \%)$ \\
Normal & $40(66.7 \%)$ \\
Total & $60(100 \%)$
\end{tabular}

Prevalence of abnormal cervical pap smear was $33.2 \%$. (Mean 4.704, df 1, $\mathrm{P}<0.05$ )

NB

ASC-US Abnormal squamous cells of undetermine significant

LSIL. Low squamous intraepithelial lesion
HSIL. High squamous intraepithelial lesion

SCC. Squamous cells carcinoma

The age distribution of the women of the women as depicted in Table-3, shows that $32(53.3 \%)$ were in the age range of 21-30 years. While those 50 years and older constituted only $(6.6 \%)$ of the studied women. Table-1 also shows that $17(28.3 \%)$ of the women attained menarche at $<15$ years of age, 15 $(25 \%)$ had their first sexual experience at $<16$ years of age with 1 out of every 3 either being in a polygamous setting or had multiple sexual partners. Multiparity was a features of most $45(75 \%)$ of the women with $25(41.6 \%)$ having used oral contraceptive pill before. The table is shown on the next page.

Table-3: Socio-demographic, risk factor, sexual and reproductive characteristics of women

\begin{tabular}{ll}
\hline Characteristics & Frequency \% \\
\hline Ages & \\
$10-20$ & $6(10 \%)$ \\
$21-30$ & $32(53.3 \%)$ \\
$31-40$ & $18(30 \%)$ \\
$41-50$ & $4(6.6 \%)$ \\
Formal education & \\
Yes & $25(41.6 \%)$ \\
No & $35(58.3 \%)$ \\
Place of living & \\
Urban & \\
Rural & $20(33.3 \%)$ \\
Age at menarche & $40(66.6 \%)$ \\
$<15 y r s$ & \\
$>15 y r s$ & $17(28.3 \%)$ \\
Age 1st sexual contact & $43(66.6 \%)$ \\
$<16 y r s$ & \\
$>16 y r s$ & $15(15 \%)$ \\
No. of sex partners & $45(75 \%)$ \\
One(1) & \\
Two(2) & \\
$>3$ & $10(16.7 \%)$ \\
Parity & $48(89 \%)$ \\
$<1$ & $2(3.3 \%)$ \\
Multiparous & \\
Oral contraceptic use & $15(25 \%)$ \\
Everer & $45(75 \%)$ \\
\hline
\end{tabular}


Abdulkadir B et al; Saudi J Pathol Microbiol, Jan, 2021; 6(1): 40-45

\section{DISCUSSIONS}

The HPV incidence of $35 \%$ out of 60 respondents obtained in this study is high, compared to the adjusted global HPV prevalence of $10.41 \%, 10.4 \%$ and $11.7 \%$ reported by Burchell et al., [10], de Sanjose et al., [11] and Bruni et al., [12] respectively. This high rate is an indication of continuous transmission of the infection and hence the importance of implementation of measures for the control of the spread of the virus and its resultant sequel in Nigeria. The result of this study was also higher than some previous reports on HPV prevalence in Nigeria; $18.6 \%$ in Osun [13] and $10 \%$ in Port Harcourt [14] but comparable with $17.0 \%$ and $18 \%$ reported among Western Africa women [15, 11]. However, some studies on HPV infection in Nigeria have reported higher prevalence Kabuga et al., [16], who reported a prevalence of $76 \%$ out of 50 women in Kano, and Maryam et al., [17], who reported a prevalence of hrHPV in Kaduna as $66.7 \%$ out of 276 women. The difference in the reported HPV rates in Nigeria may be due to various factors such as sensitivity of HPV assay used, different study population with varying exposures to different risk factors based on diverse socio-cultural differences Nwenke et al., [18].

Although there was no significant association between HPV and age, the highest prevalence was found among individuals younger than 25 years of age, and lowest among the 65 years and above age group. This pattern has been reported by some previous studies in Nigeria [19, 14]. The highest prevalence among younger age group may be an indication of sexual transmission, as it coincides with the initiation of sexual activity. Some biological mechanisms such as cervical immaturity, inadequate production of protective cervical mucus and increased cervical ectopy in younger women and adolescents could make them more susceptible to HPV infection [20].

The highest prevalence of HPV infection was found among the divorcee women. According to Idso et al., [21], one frequently accepted postulation is that divorced and separated women tend to return into dating act and new sexual partners thus increasing their risk of HPV infection. This may be an explanation for the high level of HPV infection found among this group of individuals in this study. On the other hand, AkaroloAnthony et al., [19] reported a higher prevalence of HPV among the married $(61 \%)$ over the unmarried (39\%), but a higher positivity among singles than married was reported by Thomas et al., [5]; these differences were however not significant.

The higher rate of HPV infection found among women in a polygamous relationship in this study may be because polygamy has been reported to be a factor in the spread of sexually transmitted infections like HPV $[22,23]$. The risk of HPV infection has been reported to increase with increase in the number of wives within a family [22]. The result of this study is consistent with the findings of $\mathrm{Xi}$ et al., [15].

In this study, there was no association between HPV infection and parity. This is in agreement with the previous findings of Thomas et al., [5] and Sarma et al., 24]. However, Kennedy et al., [14] found that patients with higher parity $(>3)$ had about two times higher risk of HPV infection, a report similar to that of $\mathrm{Xi}$ et al., [15] and Fadahunsi et al., [25]. The differences in the findings of these various studies is significant but according to CDC 2015, there is still insufficient data to give final conclusions about the effect of number of births on the risk of HPV infections.

There have been strong and consistent associations between numbers of new and recent sexual partners and HPV infection in female genital tract [26, 22 , 27]. In agreement with previous findings by Thomas et al., [5], the prevalence of HPV infection increases with increasing numbers of lifetime sexual partners though not statistically significant. Rivera et al., [28] and Clarke et al., [29] however showed a significantly higher HPV incidence among women with history of more than one sexual partner. Reason have been well explained by data supporting sexual intercourse as the primary route of genital HPV infection [30, 31], and increased risk of HPV acquisition from new and recent sexual partners [27].

Although the rate of HPV infection was relatively higher among participants who reported symptoms of STI than those without STI symptoms, the difference was not statistically significant. Previous study reported that cervical infection with other STIs, such as Chlamydia trachomatis, Neisseria gonorrhoeae, HSV and Trichomonas vaginalis may or aid persistence of HPV infection through immunological mechanisms Samoff et al., [32]. Nonetheless, this study did not test for any other genital infections giving no evidence to support the role of other STIs in HPV infection.

The result of this study showed no significant association of HPV infection with contraceptives use and duration of use. This result contrasts the findings of Clarke et al., [29] which recorded a significant association between HPV infection and birth control use. Intrauterine contraceptive device was mostly used among the women in this study but higher HPV infection was found among those who use condom which could mean that this population is not consistent with condom use. Similar findingsby a previous study showed that HPV infection is unrelated to the type of contraceptives used Xi et al., [15].

Cigarette smoking has been associated to be risk factor for cervical HPV infection. In this study, only $1 \%$ of individuals have ever smoked cigarette (direct smokers) and HPV infection rate was higher among them, although not significantly. Cigarette 
Abdulkadir B et al; Saudi J Pathol Microbiol, Jan, 2021; 6(1): 40-45

smoking influences epithelial immunity by decreasing the numbers of antigen-presenting Langerhans cells in the genital epithelium. Such depletion could favour HPV infection, viral persistence thus contributing to malignant transformation.

\section{CONCLUSION}

Women at higher risk of HPV infection were those with low literacy, attaining menarche $<16$ years of age, being $<16$ years at first sexual contact, having multiple sexual partners, low parity and living in rural settlement. In addition, low level of awareness about HPV infections and cervical screening was observed among the study participants despite high level of educational background, hence, a campaign to create awareness on HPV infection is urgently needed for prevention and control of the infection in Nigeria. Current HPV vaccines especially the 9-valent vaccine should have a huge possibility of reducing HPV infection and cervical cancer in Nigeria and hence should be licenced and incorporated into the routine immunization programme in the country.

\section{LIMITATIONS}

The study was conducted using cross-sectional study in the one community dominated by populations originated majorly from Katsina Local Government, which may not be generalizable to other local government areas or represent the whole state. Another important limitation is the use of self-report which may be affected by the tendency of interviewees to give socially desirable responses. However, our findings have important implications for the main areas of focus to be addressed in order to increase cancer screening despite the limitations.

\section{RECOMMENDATIONS}

This study recommends that specific awareness and perception target programs should be conducted to scale-up cervical cancer screening in this community. It is also recommend that targeted studies among other communities to compare the prevalence and factors associated with screening independently from the Katsina community.

In this way, community specific barriers to cervical screening could be identified for appropriate interventions to scale-up cervical screening.

Community highest risk factors must be identified for effective preventions and control. This study recommends that genotypes of HPV causing cancer in every area must be defined for proper preventions and treatment.

The HPV vaccines must be provided and administered prior to exposure to HPV, before first sexual activity. WHO recommends vaccination for girls aged 9-13 years as this is the cost-effective public health measure against cervical cancer.

Further studies should be done using molecular screening techniques such as the linear Array, HPV Genotyping, and molecular characterization of HPV.

\section{REFERENCES}

1. Muñoz, N., Bosch, F. X., De Sanjosé, S., Herrero, R., Castellsagué, X., Shah, K. V., ... \& Meijer, C. J. (2003). Epidemiologic classification of human papillomavirus types associated with cervical cancer. New England journal of medicine, 348(6), 518-527.

2. Gavillon, N., Vervaet, H., Derniaux, E., Terrosi, P., Graesslin, O., \& Quereux, C. (2010). "Papillomavirus human (HPV). Comment ai-je attrapé ça?". Gynaecology, Obstetrics \& Fertility. 38(3): 199.

3. Anh, P. T. H., Hieu, N. T., \& Herrero, R. (2003): Human papillomavirus infection among women in South and North Vietnam. International Journal of Cancer. 104: 213-220.

4. Molano, M., Posso, H., Weiderpass, E., van den Brule, A.J., Ronderos, M., \& Franceschi, S. (2002). Prevalence \& Determinants of HPV infection among Colombian women with normal cytology. British Journal of Cancer. 87: 324-333.

5. Thomas, D. M., Walker, P. D., Benjamins, J. A., Geddes, T. J., \& Kuhn, D. M. (2004). Methamphetamine neurotoxicity in dopamine nerve endings of the striatum is associated with microglial activation. Journal of Pharmacology and Experimental Therapeutics, 311(1), 1-7.

6. Didelot-Rousseau, M. N., Nagot, N., CostesMartineau, V., Valles, X., Ouedraogo, A., \& Konate, I. (2006). Human papillomavirus genotype distribution and cervical squamous intraepithelial lesions among high-risk women with and without HIV-1 Infection in Burkina Faso. British Journal of Cancer. 95(3):355-362.

7. Mohammed, A. Z., Edino, S. T., Ochicha, O., Gwarzo, A. K., \& Samaila, A. A. (2008). Cancer in Nigeria: a 10-year analysis of the Kano cancer registry. Nigerian Journal of Medicine. 17(3):280-4.

8. Viladomiu, M., Kivolowitz, C., Abdulhamid, A., Dogan, B., Victorio, D., Castellanos, J. G., ... \& Longman, R. S. (2017). IgA-coated E. coli enriched in Crohn's disease spondyloarthritis promote TH17-dependent inflammation. Science translational medicine, 9(376).

9. Sar Mukaddam, S. B., \& Garad, S. G. (2006): Validity of Assumption while determining sample size. Indian Journal of Community Medicine. 29(2):2004-2006.

10. Burchell, A. N., Winer, R. L., de Sanjosé, S., \& Franco, E. L. (2006). Epidemiology and transmission dynamics of genital HPV infection. Vaccine, 24, S52-S61. 
Abdulkadir B et al; Saudi J Pathol Microbiol, Jan, 2021; 6(1): 40-45

11. De Sanjosé, S., Diaz, M., Castellsagué, X., Clifford, G., Bruni, L., Muñoz, N., \& Bosch, F. X. (2007). Worldwide prevalence and genotype distribution of cervical human papillomavirus DNA in women with normal cytology: a metaanalysis. The Lancet infectious diseases, 7(7), 453-459.

12. Bruni, L., Diaz, M., Castellsagué, M., Ferrer, E., Bosch, F. X., \& de Sanjosé, S. (2010). Cervical human papillomavirus prevalence in 5 continents: meta-analysis of 1 million women with normal cytological findings. Journal of Infectious Diseases, 202(12), 1789-1799.

13. Nejo, Y. T., Olaleye, D. O., \& Odaibo, G. N. (2018). Prevalence and risk factors for genital human papillomavirus infections among women in southwest Nigeria. Archives of Basic \& Applied Medicine, 6(1), 1-12.

14. Kennedy, N. T., Ikechukwu, D., \& Goddy, B. (2016). Risk factors and distribution of oncogenic strains of human papilloma virus in women presenting for cervical cancer screening in Port Harcourt, Nigeria. Pan African Medical Journal, 23(1):85.

15. Xi, L. F., Toure, P., Critchlow, C. W., Hawes, S. E., Dembele, B., Sow, P. S., \& Kiviat, N. B. (2003). Prevalence of specific types of human papillomavirus and cervical squamous intraepithelial lesions in consecutive, previously unscreened, West- African women over 35 years of age. International journal of cancer, 103(6), 803-809.

16. Kabuga, N. A., \& Ismail, A. A. (2013). Demand for Improved Solid Waste Management among Households in the Low-income Areas of Kano Metropolis, Nigeria.

17. Maryam, A., Abbas, G., Rashid, M., \& Sattar, A. (2018). Directional mechanical and thermal properties of single-layer black phosphorus by classical molecular dynamics. Chinese Physics B, 27(1), 017401.

18. Amadi, C., Amadi, N. N., \& Nyenke, C. (2013). Public spending on transport, infrastructure and economic growth in Nigeria: 1981-2010. Journal of Sociological Research, 4 (2), 438.

19. Akarolo-Anthony, S. N., Famooto, A. O., Dareng, E. O., Olaniyan, O. B., Offiong, R., Wheeler, C. M., \& Adebamowo, C. A. (2014). Age-specific prevalence of human papilloma virus infection among Nigerian women. BMC public health, 14(1), 656.

20. Kahn, J. A., Rosenthal, S. L., Succop, P. A., Ho, G. Y., \& Burk, R. D. (2002). Mediators of the association between age of first sexual intercourse and subsequent human papillomavirus infection. Pediatrics, 109(1), e5-e5.

21. Idso, C. (2009). Sexually transmitted infection prevention in newly single older women: a forgotten health promotion need. The Journal for Nurse Practitioners, 5(6), 440-446.

22. Bayo, S., Bosch, F. X., de Sanjosé, S., Muñoz, N., Combita, A. L., Coursaget, P., ... \& Meijer, C. J. (2002). Risk factors of invasive cervical cancer in Mali. International journal of epidemiology, 31(1), 202-209.

23. Rousseau, M. C., Abrahamowicz, M., Villa, L. L., Costa, M. C., Rohan, T. E., \& Franco, E. L. (2003). Predictors of cervical coinfection with multiple human papillomavirus types. Cancer Epidemiology and Prevention Biomarkers, 12(10), 1029-1037.

24. Sarma, U., Mahanta, J., Borkakoty, B. J., Talukdar, K. L., Gogoi, R., \& Yadav, K. (2013). Demographic Characteristic of HPV Infection in Women-A Hospital Based Study from Guwahati, India. National Journal of Medical Research, 3(1), 1-4.

25. Fadahunsi, O. O., Omoniyi-Esan, G. O., Banjo, A. A. F., Esimai, O. A., Osiagwu, D., \& Clement, F. (2013). Prevalence of high risk oncogenic human papillomavirus types in cervical smears of women attending well woman clinic in Ile Ife, Nigeria. Gynecol Obstet, 3(185), 2161-0932.

26. Koutsky, L. A., \& Kiviat, N. B. (1999). Genital human papillomavirus. In: Holmes, K. K., Mardh, P. A., \& Sparling, P. F. editors. Sexually transmitted diseases. New York: McGraw-Hill; 347-59.

27. Winer, R. L., \& Koutsky, L. A. (2004). Delivering reassurance to parents: perinatal human papillomavirus transmission is rare. Sexually transmitted diseases, 31(1), 63-64.

28. Rivera, L. A. (2012). Hiring as cultural matching: The case of elite professional service firms. American sociological review, 77(6), 9991022.

29. Clarke, M. A., Gage, J. C., Ajenifuja, K. O., Wentzensen, N. A., Adepiti, A. C., Wacholder, S., ... \& Schiffman, M. (2011). A population-based cross-sectional study of age-specific risk factors for high risk human papillomavirus prevalence in rural Nigeria. Infectious agents and cancer, 6(1), 12.

30. Oriel, J. D. (1971). Natural history of genital warts. British Journal of Venereal Diseases, 47(1), $1-13$.

31. Partridge, J. M., \& Koutsky, L. A. (2006). Genital human papillomavirus infection in men. The Lancet infectious diseases, 6(1), 21-31.

32. Samoff, E., Koumans, E. H., Markowitz, L. E., Sternberg, M., Sawyer, M. K., Swan, D., ... \& Unger, E. R. (2005). Association of Chlamydia trachomatis with persistence of high-risk types of human papillomavirus in a cohort of female adolescents. American journal of epidemiology, 162(7), 668-675. 